\title{
CONTRIBUTION TO THE KNOWLEDGE OF MEALY BUGS, GENUS PSEUDOCOCCUS, IN THE VICINITY OF CAPE TOWN, SOUTH AFRICA.
}

\author{
By Chas. K. Brain, F. E. S.
}

The material studied was mainly collected by the writer during 1910 and the first part of 1911. Two of the species, however, were collected by Mr. Chas. P. Lounsbury, as mentioned in the descriptions. Sixteen different host plants are involved, but Pseudococcus capensis was found on eleven of these, while particular attention was not paid to hosts for $P$. longispinus, which was found exclusively in greenhouses. It should be mentioned that the specimens were collected as noticed while engaged on other entomological work connected with the Department of Agriculture, and it is by no means implied that the seven species mentioned in this paper include all that are present in the Cape Peninsula.

To insure more accurate measurement of the segments of the antennae, and the setae of the anal lobes and anal ring, all specimens were stained by the Carbol Fuchsin method described in a separate section of this article. The photographs and drawings were prepared by the writer hoping that they would facilitate the determination of the species. At this first opportunity I wish to express my gratitude to $\mathrm{Mr}$. Chas. P. Lounsbury, Chief of the Division of Entomology for the Union of South Africa, for much assistance in Entomological work, and also to Prof. Herbert Osborn, of Ohio State University, for his timely criticism and advice.

Pseudococcus longispinus Targ. 1867.

Dactylopius longispinus Targioni. Studi sulle Cocciniglie 1867.

Dactylopius adonidum Signoret. Essai sur les Cochenilles. Ann. Ent. Soc. Fr. 1875.

Dactylopius longifilis Comstock. Ann. Rep. Comm. Agric. 1880. Washington 1881.

This well known insect (Fig. 1) can be readily recognized by its caudal appendages, but the following particulars are added to make the series uniform and to assist in the determination of slide material.

Adult \% . Largest specimen found measured while alive $4.1 \mathrm{~mm}$., and had caudal appendages $5.5 \mathrm{~mm}$. long.

Antenna: Measurements in $\mu$. 


\begin{tabular}{l|c|c|c|c|c|c|c|c}
\hline \hline Joints & I & II & III & IV & V & VI & VII & VIII \\
\cline { 1 - 7 } Range of measurements... & $54-80$ & $58-82$ & $64-84$ & $30-50$ & $40-62$ & $30-48$ & $40-50$ & $94-110$ \\
Most common meas'rem'ts & 60.62 & 65.67 & 70.74 & 36.38 & 46.48 & 38.42 & 44 & 102 \\
Average of 20 meas'rem'ts & 64 & 70 & 71 & 39 & 50 & 40 & 45 & 101 \\
\hline
\end{tabular}

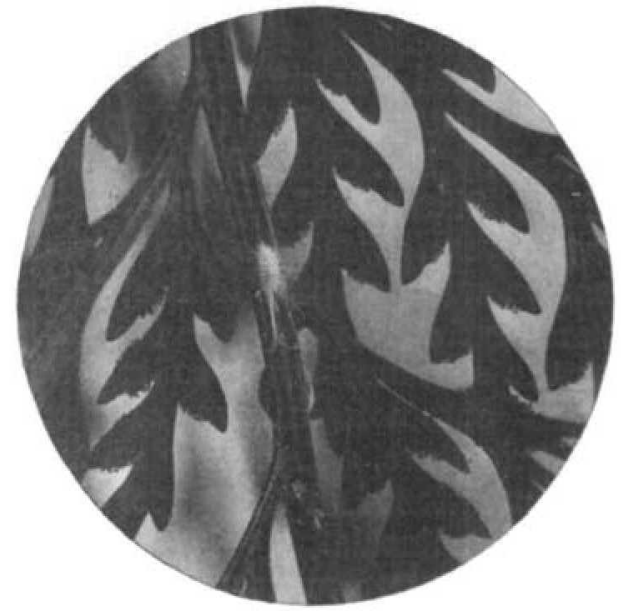

Fig. 1. Pseudococcus longispinus o length.

Setce of Anal Lobes: $110 \mu$ to $130 \mu$, with $124 \mu$ the most common

Sele of Anal Ring: $122 \mu$ to $148 \mu$ with $134 \mu$ the most common length.

Remarks: This species is commonly found on fcrns, etc., in greenhouses.

Pseudococcus citri Risso 1813.

Dorthesia citri Risso. Essai Hist. Nat. des Oranges, etc. Paris 1813.

Coccus citri Boisduval. Essai sur l'Entom. Hort. 1867.

Dactylopius citri Signoret Essai sur les Cochenilles 1875.

Dactylopius brevispinus (ex. p.) Targioni. Annali di Agricoltura 1881.

Dactylopius destructor Comstock. Ann. Rep. Comm. Agr. 1880. Washington, 1881.

This species-the common mealy-bug of literature-is easily distinguished from $P$. longispinus by the absence of the long caudal filaments, and from the other species of the locality by the fact that the waxy secretion is most scant down the median dorsal line. Its general appearance is well shown in Plate XIV, Fig. 3, which is greatly enlarged. The seventeen lateral wax appendages are often more or less wanting in old rubbed specimens, especially those living in exposed positions.

Ovisac: Small, more or less spherical, at first covered by the body of the female. As the mass increases it is generally seen as a rounded: mass protruding beneath, and in front of, the insect. 
Ova: Amber yellow, 320-350 $\mu$ long, and $146-165 \mu$ broad.

Adult $\%$ : Largest specimen found, with ovisac completed, measured while alive $4.45 \mathrm{~mm}$. long by 2 . (it $\mathrm{mm}$. broad.

Antenne: Plate XV, Fig. $J$. Antennal segments, measurements in $\mu$.

\begin{tabular}{|c|c|c|c|c|c|c|c|c|}
\hline Join & I & 11 & 111 & 18 & $v$ & VI. & V11 & VIII \\
\hline $\begin{array}{l}\text { ost common meas'r'm ts } \\
\text { rerage of } 30 \text { meas'r'm'ts. }\end{array}$ & $\begin{array}{c}52-7 t \\
60,66 \\
62.6\end{array}$ & $\begin{array}{c}58-76 \\
62,65 \\
64 . \overline{5}\end{array}$ & $\begin{array}{c}52-70 \\
60,65 \\
64\end{array}$ & $\begin{array}{c}34-16 \\
42 \\
39.3\end{array}$ & $\begin{array}{c}36-48 \\
42 \\
\mathbf{4 3 . 3}\end{array}$ & $\begin{array}{c}36-48 \\
44 \\
42.8\end{array}$ & $\begin{array}{c}40-54 \\
46 \\
47.5\end{array}$ & $\begin{array}{c}96-120 \\
108 \\
106.6\end{array}$ \\
\hline
\end{tabular}

Sete of A nal Lobes: 18()$\mu$ to $270 \mu$ with $225 \mu$ the commonest length"

Setee of Anal Ring: $10 \mathrm{~S}-13 \mathrm{~S} \mu$ with $115 \mu$ the commonest length.

The distribution of spines and pores round the anal lobes is shown in Plate XVI, Fig. 1.

Remarks: P. citri is one of the greatest worries of nurserymen on Coleus, and was also quite common in the Cape Peninsula on Oleander.

\section{Pseudococcus lounsburyi n. sp.}

Ovisac: When complete entirely enclosing the adult $ᄋ$, large, elongate, oval, composed of threads which, when seen under the microscope have almost a glassy appearance; $4.5 \mathrm{~mm}$. long, by $2.25 \mathrm{~mm}$. broad. Large numbers of ovisacs were often found matted together between leaf-bases, sometimcs forming a mass two inches long by almost as wide.

Ova: Closely surrounded by fibres of the ovisac; orange ycllow, $340 \mu$ long by $176 \mu$ in diameter.

Larve: Newly emerged, are nearly transparent, showing but the slightest tinge of the usual purplish coloring $680 \mu$ long and $260 \mu$ broad; antennæ transparent, of 6 joints.

If ale: Puparium small, brownish whitc. Adult of the usual Pseudococcus $\sigma^{x}$ form (see figure) with body purplish red in color, .9 to $1.020 \mathrm{~mm}$. in length and $.255 \mathrm{~mm}$. across the thorax, the widest part of the body; legs and antennæ pale yellow, and semi-transparent. Antenna of 10 joints, $.564 \mathrm{~mm}$. long, eyes black; caudal appendages, when living, two stout, $.255 \mathrm{~mm}$. long, and two more slender, nearly half as long. Males emerge November and early. December.

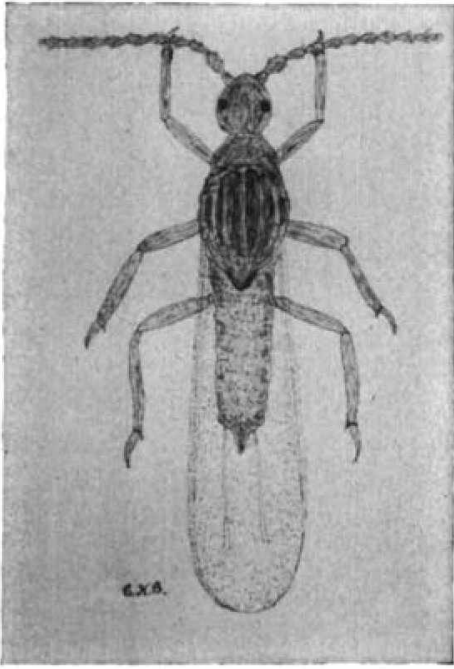

Fig. 2.

$\sigma^{7}$ of Pseudococcus lounsburyi, greatly enlarged. 
Adult Female: At the time of spinning the ovisac, large, $3.7 \mathrm{~mm}$. (4.1 $\mathrm{mm}$. with caudal appendages) by $1.65 \mathrm{~mm}$. broad, becoming somewhat narrower towards the anterior and posterior ends; color purplish, showing distinctly through the ashy white secretion; segmentation very distinct; legs and antennæ very pale; lateral wax appendages absent, caudal ones stout at base, somewhat conical, snow white, and appearing granular. Inner pair longer and stouter than the outer ones. Until the females attain approximately the size $2.4 \mathrm{~mm}$. long by $1.1 \mathrm{~mm}$. broad they remain free-moving. (Plate XIV, Fig. 4). After this the ovisac is commenced-a silky mass which ultimately completely envelopes the insect. This is spun from the posterior end forward, as shown in Figs. 5 and 6 , until, in the end, it forms a complete covering for the female, and later the ova.

Antennce: Plate XV, Fig. 6.

Segments-measurements in $\mu$.

\begin{tabular}{l|c|c|c|c|c|c|c|c}
\hline \hline Joints.............. & I & II & III & IV & V & VI & VII & VIII \\
\hline Range of measurements.... & $56-66$ & $64-72$ & $43-52$ & $26-36$ & $33-48$ & $26-30$ & $36-42$ & $88-100$ \\
Most common meas'r'm'ts & 60 & 68 & 46 & 28 & 42 & 28 & 36 & $88-92$ \\
Average of 10 meas'r'm'ts. & 61 & 69 & 47 & 28 & 42 & 28 & 37 & 92 \\
\hline
\end{tabular}

Seta of Anal Lobes. $144 \mu$ to $160 \mu$ long (from 5 measurements).

Sete of Anal Ring. $104 \mu$ to $128 \mu$ long.

Unfortunately, although 35 specimens were mounted, nearly all the seta of the anal lobes were lacking. It commonly happens in clearing specimens in $\mathrm{K} \mathrm{O} \mathrm{H}$ etc., that a number of the hairs, spines, etc., are lost but $I$ have never found it occur to such an extent as in this species. Plate XVI, Fig. 2 shows the distribution of spines and pores round the anal lobes.

Type Slide: On this slide are three specimens, arranged, with the slide in front of one as labeled, in the form of a triangle. The insect at the apex is here described as "a," the one at the left as " $b$," and the one on the right as "c."

Specimen " $a$ ": Size, mounted, $2.8 \mathrm{~mm}$. long by $1.4 \mathrm{~mm}$. broad.

Pores of derm small and scattered, sparingly supplied with small hairs, especially across the middle zones of segments. Hairs on dorsal surface more numerous and longer, sometimes attaining length of $90 \mu$.

Antennal segments: One antenna folded. Segments of other, in order 1 to 8 , measured in $\mu$ are $58,68,48,36,42,27,36$ and 89 . It should be mentioned that Segment IV, measuring, in this specimen $36 \mu$ is the longest found in the whole series. The usual length for joint IV is about $28 \mu$.

Sete of Anal Lobes. $154 \mu, 160 \mu$.

Setce of Anal Ring: About $128 \mu$.

Legs: The measurements of the legs on the right side of the insectleft side as mounted with ventral side up are given in $\mu$. It should be noticed that seven measurements are given, and the illustration shows the scheme adopted. The Coxa and trochanter are unsatisfactory as 
regards measuring in many instances and the method adopted in the scheme used here is to obtain measurements in direct lines from points which remain definite with different ways of folding of the legs in mounting. Hence the trochanter is measured with the femur.

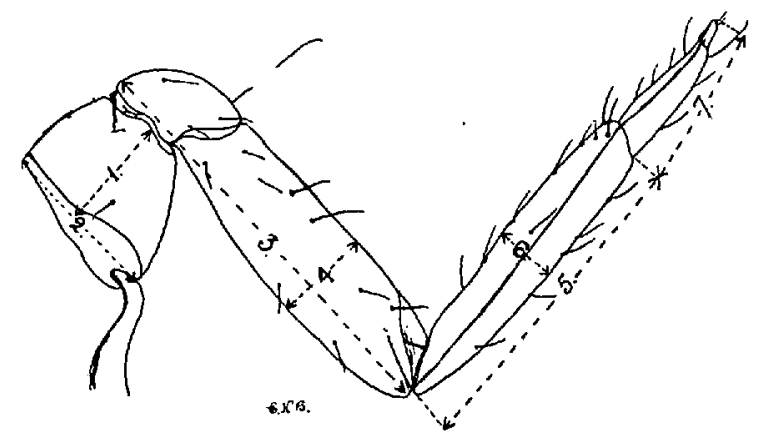

Fig. 3.

Right metathoracic leg of Pseudococcus lounsburyi 우 illustrating scheme of measurments.

The measurements in $\mu$ are given in the following order:

1. Length of coxa.

2. Breadth of coxa across base.

3. Length of trochanter plus femur.

4. Breadth of femur.

5. Length of tibia.

6. Brcadth of tibia.

7. Length of tarsus plus claw.

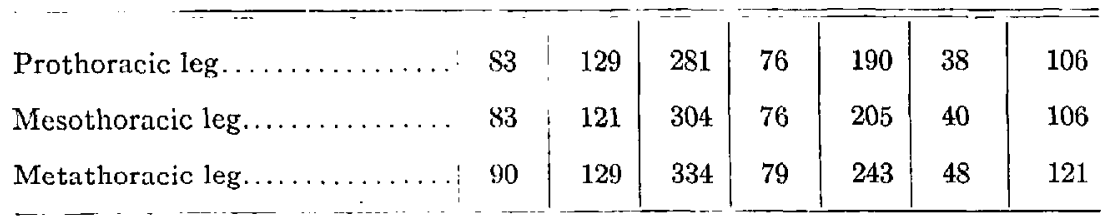

Specimen " $b$ ": Size mounted $3.2 \mathrm{~mm}$. by $1.6 \mathrm{~mm}$.

The measurements of the segments of the antenna (one lacking) in this insect illustrate a very good average for the material collected. They are: $58,64,44,26,42,28,36$ and $91 \mu$. The Setæ of the anal lobes unfortunately are missing, while those of the anal ring average from $120 \mu$ to $128 \mu$.

Specimen " $c$ ": Size mounted $3 \mathrm{~mm}$. by $1.5 \mathrm{~mm}$.

Antennal Segments: Right-56, 64, 43, 28, 33, 27, 38, 88. Left$62,64,43,27,38,28,36,88$.

The fifth segment of the right antenna in this insect measures only $33 \mu$. It is a coincidence that this is the least measurement found for this segment, and it is on the same slide as the specimen showing the maximum length for segment IV. One of the setæ of the anal lobes is missing. The one remaining measures $156 \mu$, while those of the anal ring average about $108 \mu$. 
Host Plant: Agapanthus umbellatus L'Hérit.

Remarks: This species was first found by Mr. C. P. Lounsbury on the leaf-bases of this plant in the grounds of Indian House, Kenilworth, on September 10, 1910.

\section{Pseudococcus capensis n. sp.}

Ovisac: Large, $4.2 \mathrm{~mm}$. long by $3 \mathrm{~mm}$. broad, white, fibrous.

Ova: Bright orange yellow, $344 \mu-390 \mu$ long by $170 \mu-190 \mu$ broad.

Adult o : Largest specimens found were $4.2 \mathrm{~mm}$. long and $3.4 \mathrm{~mm}$. broad. Waxy secretion usually scant, lateral filaments short and very slender; caudal ones (2), when insect is in sheltered spot, sometimes attaining half the length of body.

Antenne: Plate XV, Fig. 3.

Scgments, measurements in $\mu$.

\begin{tabular}{l|c|c|c|c|c|c|c|c|c}
\hline \hline Joints................ & I & II & II I & IV & V & VI & VII & VIII \\
\hline Range of measurements.... & $60-76$ & $76-90$ & $76-92$ & $36-50$ & $52-64$ & $36-45$ & $40-52$ & $96-115$ \\
Most common meas'r'm'ts & 68 & 80 & 80 & $40-42$ & $56-62$ & 40 & 44 & 104 \\
Average of 20 meas'r'm'ts. & 68 & 81.5 & 81 & 42 & 59 & 39 & 44 & 105.5 \\
\hline
\end{tabular}

Seta of Anal Lobes: $117 \mu-152 \mu$, most common length about $128 \mu$.

Seta of A nal Ring: $154 \mu-180 \mu$, most common length about $160 \mu$.

Plate XVI, Fig. 3, shows distribution of glands, etc., round anal ring.

Type: Size mounted $3 \mathrm{~mm}$. by 1.86. Dermis with small scattered pores on ventral surface, with scant short hairs. Dorsal surface with scattered, large pores, some at anterior cnd with hairs reaching $96 \mu$ in length.

-Antenna: Segments, Right-70?, 80, 72, 50, 53, 40, 43, and $110 \mu$. Left-75?, 80, 75, 45, 56,42,43, and $107 \mu$.

Setee of Anal Lobes about $117 \mu$ long, those of Anal Ring about $160 \mu$ long.

Legs: measurements in $\mu$.

\begin{tabular}{|c|c|c|c|c|c|c|c|}
\hline Prothoracic leg. & 83 & 129 & 304 & 91 & 228 & 38 & 114 \\
\hline Mesothoracic leg.. & 98 & 129 & 327 & 91 & 258 & 38 & 121 \\
\hline Metathoracic leg.. & 98 & 129 & 357 & 95 & 311 & 53 & 129 \\
\hline
\end{tabular}

Remarks: This species was found on a number of different host plants, viz.: Phytolacca dioica Piper, Albizzia lophantha, Solanum sodomceum Linn., Clematis vitalba, Pelargonium sp., Sonchus oleraceus Linn., Senecio vulgaris Linn., Malva parviflora Linn., and Oxalis cernua Thunb. It was also found on vines at Constantia and on stored pumpkins at Stellenbosch. The following notes made at the time of collecting the material illustrate some phases of the life-history of this species: 
(a) On Phytolacca dioica Piper, at Rosebank Station. July 17, 1911. Fruit clusters nearly all fallen. These were heavily infested with Mealy Bug, and on falling to the ground many of the adult females made their way back to the trunks of the trees. At this date many females are to be seen walking about the bark, while the trunks are quite noticeable from the number of ovisacs spun in the cracks of the bark. In the four trees there must be some thousands of ovisacs within five feet of the ground, while in one case they are numerous to a height of 25 to 30 feet.

(b) On Albizzia lophantha. In winter this species is commonly clustered on the crowns of young seedling plants of this species immediately below the surface of the ground. Others are found in cracks in the bark of larger trees and later in the season when the leaves and flowers appear the insects are scattered over the whole tree. Large numbers of ovisacs have been found matted together in the seed pods.

(c) On Stored Pumpkins at Stellenbosch. Dec. 15, 1910. On this date I collected full-grown females $(3-4 \mathrm{~mm}$.) from pumpkins of the Turk's Head variety which had been stored on a roof (galvanized iron) for some months. Numerous completed ovisacs were present. All specimens were below the pumpkins and had the appearance of having remained there for a long time. The pumpkins were exceedingly hard and dry and were on a hot, dry, exposed roof, but the insects were quite healthy looking and lively.

(d) On Vines at Constantia. Jan. 3, 1911. This material was collected by Mr. C. P. Lounsbury who states that at this date females of all stages were present in the vines but very few had entered the bunches themselves, which were small at that time.

\section{Pseudococcus wachendorfiæ n. sp.}

Ovisac: No definite ovisac was found, although where the adult $q$ was situated a dcfinite white granular patch of waxy secretion was noticed on the plant.

1dult 으: Largest specimen found measurcd while alive $4.1 \mathrm{~mm}$. long and $1.9 \mathrm{~mm}$. broad. The body was finely covered with granular secretion, white, but segmentation was still conspicuous. Lateral appendages of wax were absent, but a short caudal tuft was generally noticeable.

Antenne: Plate XV, Fig. 2.

Segments: Measurements in $\mu$. 


\begin{tabular}{l|c|c|c|c|c|c|c|c}
\hline Joints................. & I & II & III & IV & V & VI & VII & VIII \\
\hline Range of measurements.... & $60-68$ & $44-64$ & $32-56$ & $18-26$ & $28-44$ & $20-28$ & $28-36$ & $66-96$ \\
Most common meas'r'm'ts & 60 & 60 & 44 & 24 & 36 & 24 & 28.32 & 80 \\
Average of 10 meas'r'm'ts. & 64 & 56 & 43 & 23 & 36 & 24 & 31 & 78 \\
\hline
\end{tabular}

Sete of Anal lobes: $154 \mu-180 \mu$ with commonest length about $160 \mu$. Setee of Anal ring: $115 \mu-144 \mu$ with commonest length about $136 \mu$. Plate XVI, Fig. 4, shows distribution of pores etc., round anal lobes. Type: Specimen mounted measures $2.7 \mathrm{~mm}$. long by $1.8 \mathrm{~mm}$. broad.

Dernis, with numerous scattered pores and numerous short hairs or spines, especially along the median zones of the segments. On the dorsal surface, towards the anterior end, the hairs are numerous and longer, some reaching $72 \mu$ in length.

Antenna: The segments measured in $\mu$ are: ?, $53,43,25,28,27,32$ and $80 \mu$ on one side, and $64,56,44,22,32,26,31$ and $80 \mu$ on the other. The Seta on the anal lobes are $155 \mu$ and $158 \mu$ while those of the anal ring average about $136 \mu$.

Legs: Measurements in $\mu$.

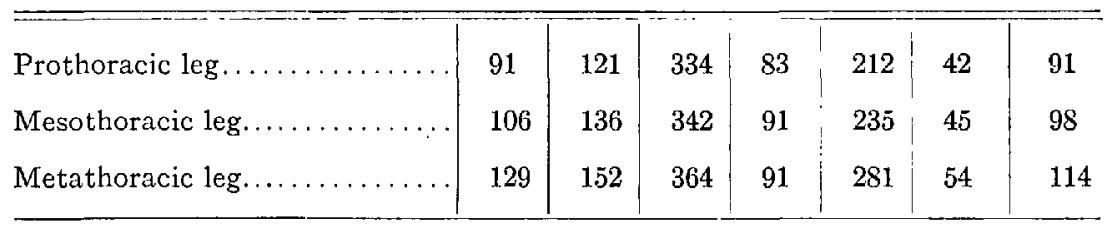

Remarks: This species was only found on Wachendorfia paniculata Linn. The material was collected by the writer on Newlands Flats, about eight miles from Cape Town, on October 3,1910 . The mealy-bug was found on thirty per cent of the plants of this kind pulled up in an area of about two hundred yards square, but was not once found above the surface of the ground. It was between the leaf-bases, and extended from half to one and a half inches down. The ground was composed of white sand. Ants were in constant attendance and had in some cases raised the sand slightly around the stem of the plant. It was this fact that attracted my attention. It was noticeable that some half-mile away, where the plant was fairly plentiful again, no mealy-bug could be found. It might be suggested that the colonies of ants have something to do with the distribution as the plants are generally somewhat scattered.

\section{Pseudococcus muraltiæ n. sp.}

Ovisac: Spherical, $2.3 \mathrm{~mm}$. in diameter, white, fibrous. Large clusters of ovisacs occur sparingly, and are generally overrun by ants. Plate XIV, Fig. 1 shows such a cluster three-fourths natural size. wide.

Ova: Orange yellow in color, oval, averaging $240 \mu$ long by $180 \mu$ 
Larva: (a) newly hatched, orange yellow, legs and antennæe pale, transparent. The larvæ in this stage are very active, oval in form, measuring $358 \mu$ long by $170 \mu$ broad. (b) later, $544 \mu$ long by $255 \mu$ broad. Antennæ of 6 joints, about $170 \mu$ long. Eyes conspicuous, black. Measurements of the larval antennæe in $\mu$ gave the following lengths for the segments: $20,22,16,18,20$ and $68 \mu$. Larvæ began to emerge from ovisacs kept at room temperature on October 25 th.

Male: not found.

Adult 우: (Plate XIV, Fig. 2) small; largest specimen, with completed ovisac, was $1.9 \mathrm{~mm}$. long by $1.13 \mathrm{~mm}$. broad, slatey-gray in color; waxy secretion scant but segmentation conspicuous. Lateral appendages were absent but usually four caudal ones present, the longest of which measured $330 \mu$. Color in boiling $\mathrm{K} \mathrm{O} \mathrm{H}$ black, then purple.

Antenne: Plate XV, Fig. 1.

Segments: measured in $\mu$.

\begin{tabular}{l|c|c|c|c|c|c|c|c}
\hline Joints..................... & I & II & III & IV & V & VI & VII & VIII \\
\hline Range of measurements.... & $32-42$ & $34-40$ & $26-34$ & $16-23$ & $21-25$ & $20-24$ & $25-32$ & $72-84$ \\
Most common meas'r'm'ts & 40 & 38 & 30 & 20 & 24 & 22 & 28 & 82 \\
Average of 10 meas'r'm'ts. & 39 & 38 & 31 & 20 & 23.5 & 22 & 29 & 82 \\
\hline
\end{tabular}

Setce of Anal Lobes: $120 \mu-150 \mu$, most common length about $130 \mu$.

Seta of Anal Ring: $96 \mu-120 \mu$, most common length about $108 \mu$.

Plate XVI, Fig. 5 , shows the distribution of spines, etc., round anal lobes.

Type Slide: This slide has two specimens mounted on it, but the one to the left as slide is labeled is considered the type specimen. (Specimen A).

Specimen A: Size mounted $1.6 \mathrm{~mm}$. by $1.14 \mathrm{~mm}$.

Dermis: Pores very scattered. Those on the dorsal surface generally larger than those of ventral surface. On both surfaces are a few scattered hairs. Some of these on the dorsal surface, towards the anterior end are long and very slender, reaching in a few cases $90 \mu$ long.

Antenna: Right-34?,34, 26, 20,24, 20, 25 and $78 \mu$. Left- 40 , $35,26,16,24,20,25$, and $80 \mu$.

The setæe of the anal lobes are $128 \mu$ long, while those of the anal ring average about $112 \mu$.

Legs, measured according to scheme given with description of $P$. lounsburyi are:

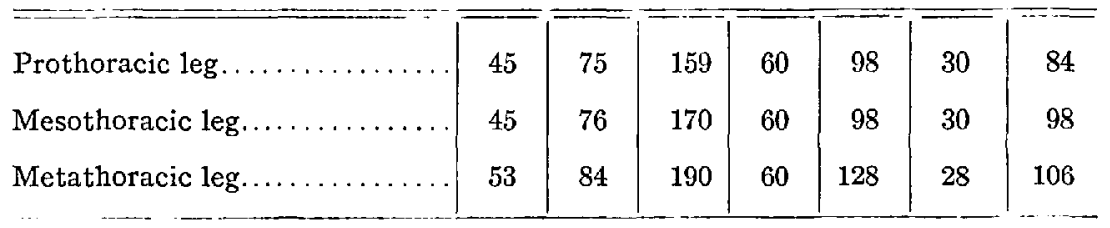

Specimen $B$. Size mounted is $1.67 \mathrm{~mm}$. long and $1.18 \mathrm{~mm}$. broad.

Antenne: Right-?, 36, 32, 17, 24, 22,30 and $72 \mu$. Left-?, 38, $31,16,24,20,27$, and $78 \mu$. 
The Setæ of the anal lobes are $128 \mu$ and $134 \mu$ long while those of the anal ring seem to vary between $98 \mu$ and $104 \mu$.

Host Plant: Muraltia heisteria, D. C.

Remarks: As far as is known this small species has only the one host plant. It was found by the writer on the Cape Flats east of Newlands and Rondebosch.

\section{Pseucdooccus fragilis n. sp.}

This material was collected on oranges at Constantia by Mr. C. P. Lounsbury on October 19, 1910. Unfortunately, I have no notes with me concerning the living insect, and have no particulars of the ovisac, etc. The insect is so distinct from the other species collected in the district, however, that I will give the measurements from the slide material, and hope to complete the description on my return to the Cape.

Adult $q$ : Size of largest mounted specimen $4 \mathrm{~mm}$. long and 2.4 $\mathrm{mm}$. broad. The integument appears exceptionally delicate, the antennæe unusually long, (Plate XV, Fig. 4) and the spines and setæe unusually thin and fragile, and, in mounted specimens, very much bent.

Antennal Segments:

\begin{tabular}{l|c|c|c|c|c|c|c|c}
\hline \hline Joints.................. & I & II & III & IV & V & VI & VII & VIII \\
\hline Range of measurements.... & $64-70$ & $72-90$ & $80-100$ & $56-62$ & $60-84$ & $50-64$ & $48-60$ & $104-120$ \\
Most common meas'r'm'ts & 64 & 76 & 88 & 58 & 64 & 52 & 56 & 112 \\
Average of 10 meas'r'm'ts. & 66 & 80 & 90 & $\mathbf{5 7}$ & $\mathbf{7 0}$ & $\mathbf{5 3}$ & $\mathbf{5 5}$ & $\mathbf{1 1 4}$ \\
\hline
\end{tabular}

Seta of Anal Lobes are about $230 \mu$ long.

Sete of Anal Ring are about $192 \mu$ long.

Plate XVI, Fig. 6, shows the distribution of spines, etc., round the anal lobes.

Type: Size mounted $4.0 \mathrm{~mm}$. by $2.4 \mathrm{~mm}$.

The pores and hairs on the dermis are scant and the latter are very thin. Near the anterior end, on the dorsal surface are a number of long delicate hairs, some of which reach a length of $160 \mu$ or possibly more.

The Antennal Segments measure: Right-64, 84, 96, 58, 74, 54, 51, $118 \mu$. Left-64, 80, 96, 60, 80, 50, 56, $116 \mu$.

The Setæ of the anal lobes measure approximately $224 \mu$ long, while those of the anal ring probably average about $196 \mu$ in length.

Legs measured according to scheme given for P. lounsburyi.

\begin{tabular}{|c|c|c|c|c|c|c|c|}
\hline Prothoracic leg....... & 121 & 167 & 364 & 106 & 250 & 38 & 136 \\
\hline Mesothoracic leg..... & 129 & 167 & 417 & 102 & 304 & 38 & 144 \\
\hline Metathoracic leg.. & 129 & $159 ?$ & 432 & 106 & 342 & 45 & 144 \\
\hline
\end{tabular}

Host Plant: Orange. 
STAINING COCCIDAE FOR DETERMINATION, WITH SPECIAL REFERENCE TO THE GENUS PSEUDOCOCCUS.

During 1910, and the first part of 1911 the writer collected material in the vicinity of Capetown, South Africa, for the purpose of determining what species of the Genus Pseudococcus Westwood, were to be found in that locality. Specimens were obtained from twenty-one different kinds of plants, and a series of experiments made to determine which was the most satisfactory way of mounting them for study. Everyone who has worked with this genus will appreciate the difficulties encountered in the determination of species, and also the unsatisfactory nature of the majority of the descriptions given for described species. Most of these descriptions simply give the size, color, amount of waxy covering, antennal formula and host plant. If different descriptions of the same species are available it will at once be seen how variable are the facts given. Smith* (1911) discusses this fact and shows the futility of many of the specific characters generally used.

Notwithstanding the fact that the mere antennal formula is of little value, the relative size of the antennæ as a whole, and of the segments separately, is a very useful character when the actual measurements are given. This, together with the average size of the adult $\&$ at the time of oviposition, the comparative lengths of the setre of the anal lobes with those of the anal ring, the nature of the integument and the distribution of pores and spines, furnish, I believe, the best characters obtainable.

For all these characters, except the length of the individuals, specimens cleared and mounted in the usual manner are not the most satisfactory. With regard to the joints of the antennæ especially does this apply, for such specimens are too clear, and the distinction between the joint itself and the conjunctiva is indistinct. Referring to this fact, Smith (loc. cit. p. 313) states: "The chitin is not continuous from one segment to the next and consequently the portion between the chitinous parts of the segments, the conjunctiva, is not visible or only slightly so in well cleared specimens. Consequently, in making

P. E. Smith. "Specific Characters of the Genus Pseudococcus." Ann. Ent. Soc. Am. IV, No. 3. Sept., 1911. 
measurements, the determination of the end of a segment will be only approximately at the center of the conjunctiva. This difficulty will be increased if there are some bends in the antennæ."

To overcome this difficulty a number of methods of staining were tried, but the one given below proved the most satisfactory and gave excellent mounts.

Puncture the specimens with a coarse needle or the point of a fine scalpel and treat with $\mathrm{K} \mathrm{O} \mathrm{H}$ in the usual manner. After washing in water transfer to strong Carbol fuchsin and leave until deeply stained. Specimens may be left in this for an hour or more, or over night if the stain is diluted. Wash in weak alcohol and bring up to $95 \%$ or absolute alcohol. By the time this stage is reached the specimens should be uniformly deeply colored but translucent. Place in clove oil to clear and bleach. The action of this is slow, and the condition of the specimens can be regulated so that any degree of staining can be retained. If left sufficiently long the integument will be quite clear except for the more highly chitinised parts, i. e., antennæ, legs, mouthparts, spines and pores. At this stage the specimens make exceedingly beautiful slides and quite satisfactory mounts to work with. Specimens should be passed from clove oil through xylol into balsam. The illustration shows a photograph from such a mount.

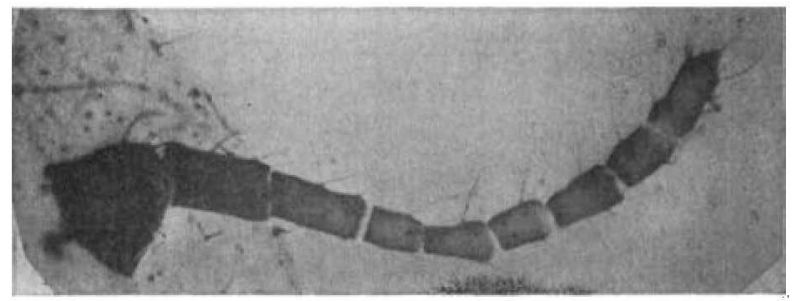

Fig. 4. Microphotograph of right antenna of Pseudocaccus $\mathrm{sp}$. showing pseudo-articulation of segment viii.

Armoured scales, (also Mallophaga, Pediculidæ and other soft-bodied insects) may also be improved for purposes of study by a very simple method. After treating with $\mathrm{K} \mathrm{O} \mathrm{H}$ and bringing through the alcohols the specimens should be cleared in Beechwood Creosote to which a little Picric Acid has been added. This turns the creosote a bright brown but does 
not interfere with its clearing properties. By this means chitin is stained a bright sulphur yellow. From this the specimens may be mounted direct, but are probably better when passed quickly through xylol or clear creosote into balsam.

\section{EXPLANATION OF PLATES.}

Pla'ce XIV. Fig. 1. Cluster of ovisacs of Pseudococcus muraltiæ $\frac{1}{4}$ nat. size. Fig. 2. P. muraltia, \&. Fig. 3. P. citri. Fig. 4. P. lounsburyi, 9 \% , before ovisac :s begun. Fig. 5. P. lounsburyi, $\%$, with ovisac begun. Fig. 6. A slightly later stage.

Plate XV. Antennae. Camera lucida drawings, all of equal magnification, for comparison of size..

Plate XVI. Fig. 1. Pseudococcus citri. Fig. 2. P. lounsburyi.

Fig. 3. P.capensis. Fig. 4. P. wachendorfia. Fig.5. P. muraltia.

Fig. 6. P. fragilis.

\section{NEW POSTAL REGULATIONS.}

The following statement of the revised regulations of the Postoffice department concerning the transmission of insects through the mails has been kindly supplied by Dr. L. O. Howard, Chief of the Bureau of Entomology:

"Queen bees and their attendant bees, when accompanied by a certificate from a State or Government inspector that they have been inspected and found free of disease; beneficial insects, when shipped by departments of entomology in agricultural colleges and persons holding official entomological positions; other live insects, when addressed to the Bureau of Entomology of the United States Department of Agriculture, to departments of entomology in State agricultural colleges, and to persons holding official entomological positions, and dried insects and dried reptiles may be sent in the mails when so put up as to render it practically impossible that the package shall be broken in transit, or the persons handling the same be injured, or the mail bags or their contents soiled.

“Nursery stock, including field-grown florists' stock, trees, shrubs, plants, vines, cuttings, grafts, scions and buds (which may carry injurious insects) may be admitted to the mails only when accompanied by a certificate from a State or Government inspector to the effect that said nursery stock has been inspected and found free from injurious insects." 


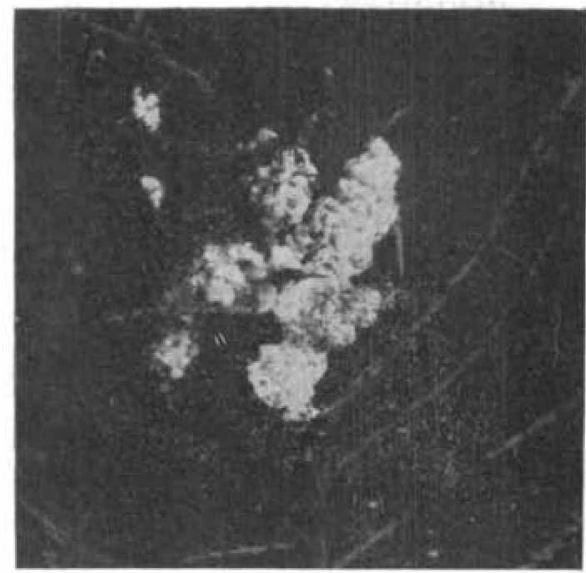

1. Ovisacs of P. muraltiae.

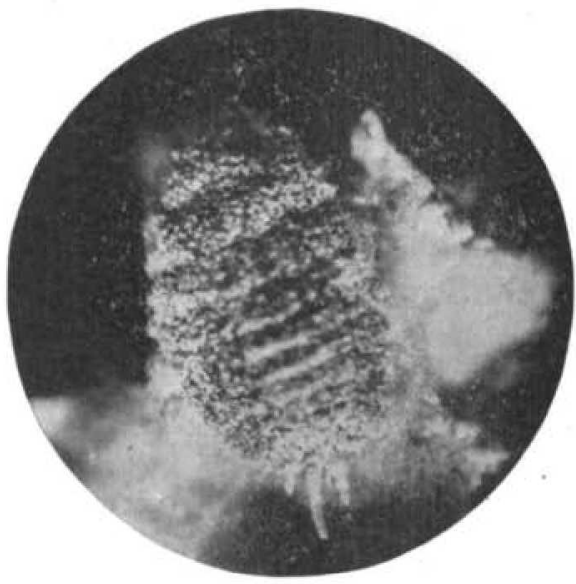

2. P. muraltiae.

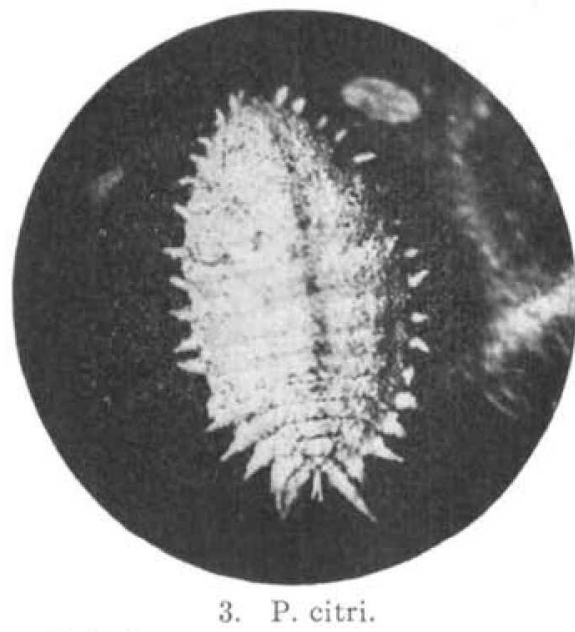

C. K. Brain.

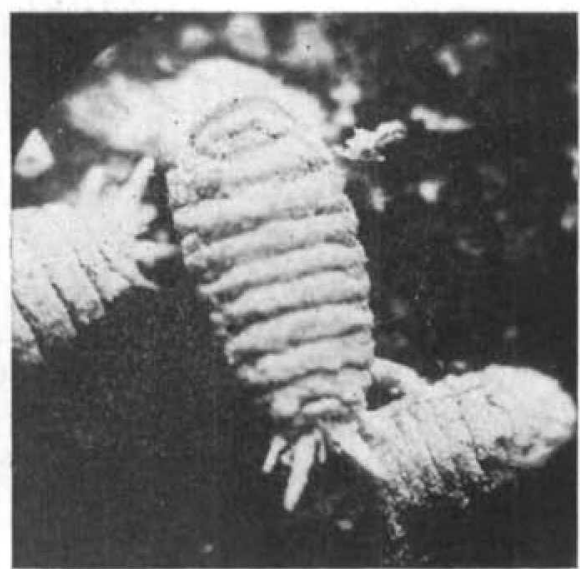

4. P. lounsburyi.

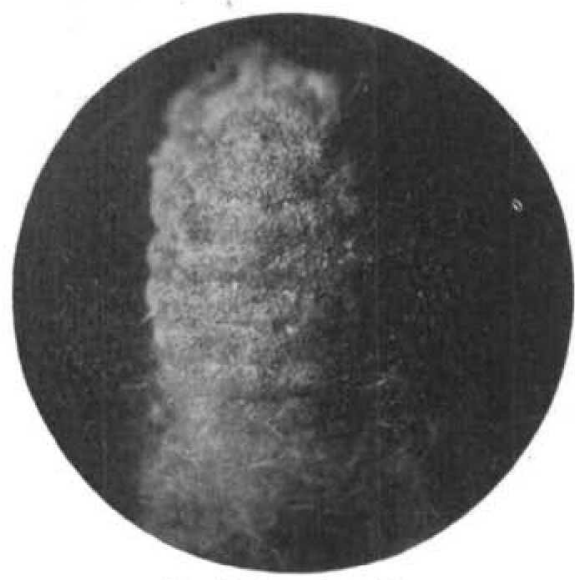

5. P. lounsburyi.
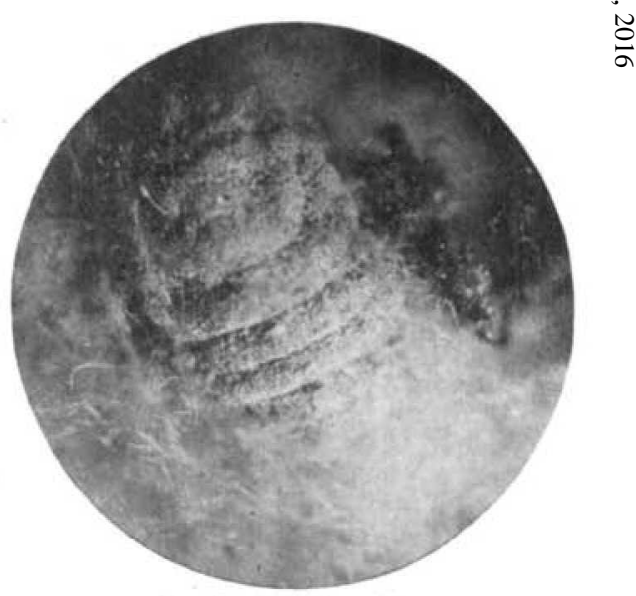

6. P. lounsburyi. 
ANNALS E. S. A.

Vol. V, Plate XV.
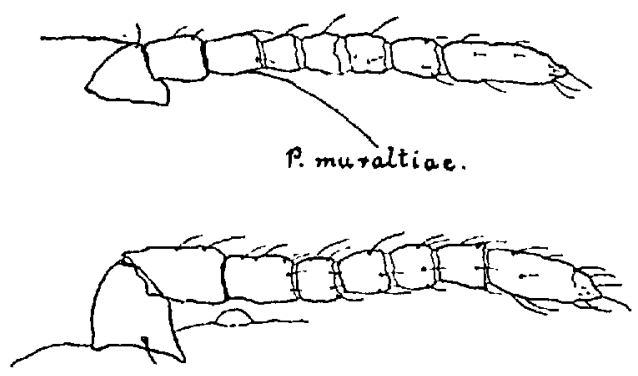

P. wachendorfiae.

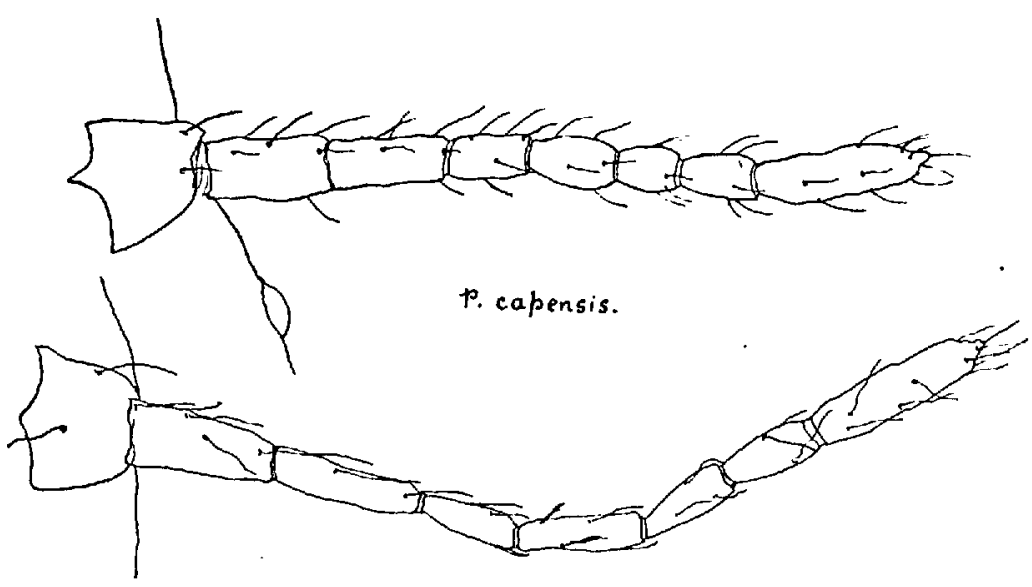

P. ftagitis.
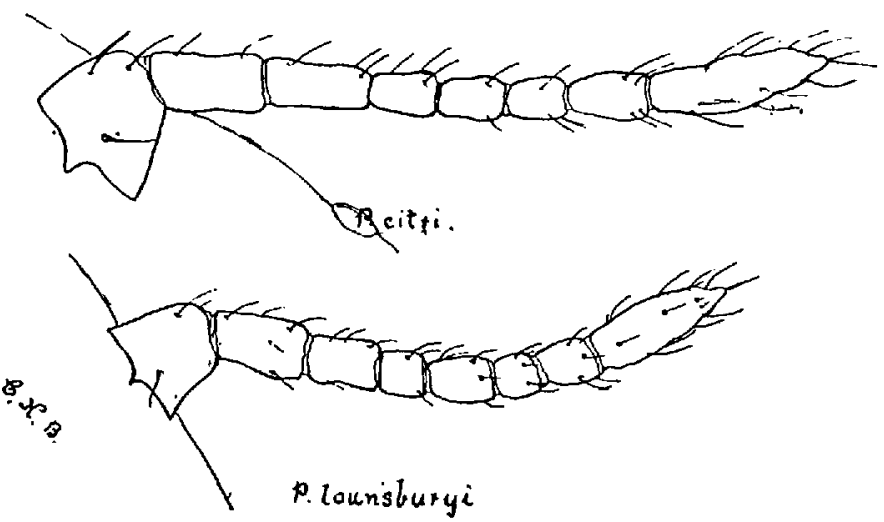

C. h. Brain, 

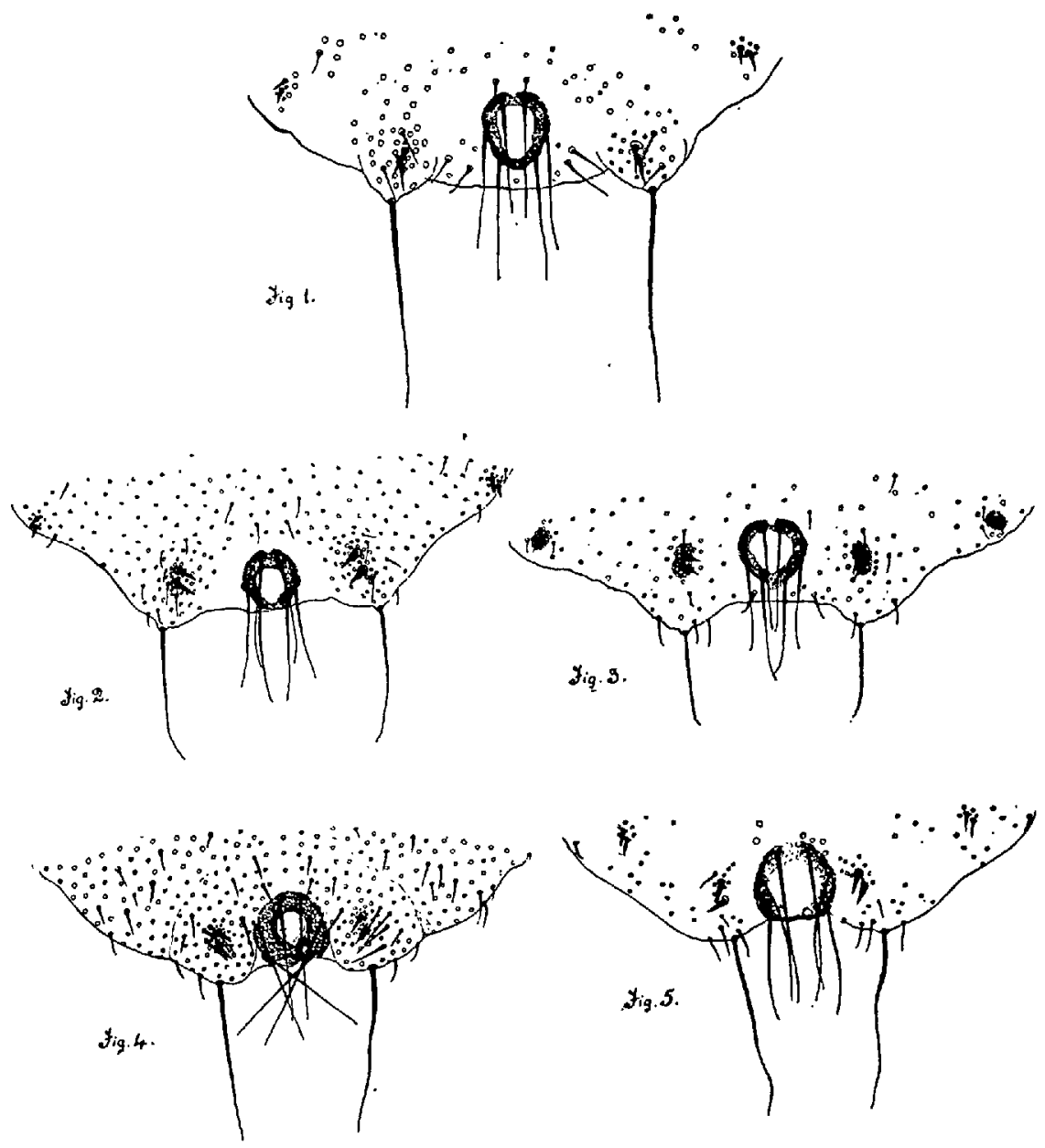

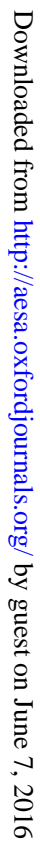

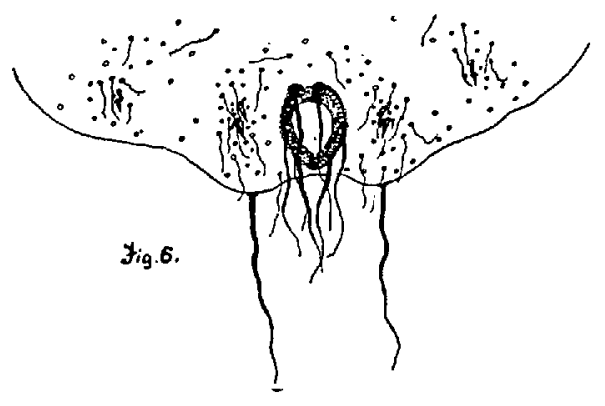

